\title{
Electrical Conductivity and Thermal Properties of Functionalized Carbon Nanotubes/Polyurethane Composites
}

\author{
Aline M. F. Lima, Vinícius G. de Castro, Raquel S. Borges, Glaura G. Silva \\ Departamento de Química, UFMG
}

\begin{abstract}
Multi-walled carbon nanotubes (MWCNTs) functionalized with amine and carboxyl groups were used to prepare polyurethane/ MWCNT nanocomposites in two distinct concentrations: a lower value of 1 mass $\%$ (spray coating) and a higher one of $\sim 50$ mass $\%$ (buckypaper based). The MWCNT-NH ${ }_{2}$ sample contained only 0.5 mass $\%$ of amine groups, whereas MWCNT-COOH contained 5 mass $\%$ of carboxyl groups. The MWCNT functionalized with low amine group content showed improved thermal properties when compared to neat thermoplastic polyurethane (TPU) and MWCNT-COOH based nanocomposites. The electrical conductivity of the polyurethane elastomer was greatly increased from $10^{-12}$ to $\sim 10^{-5} \mathrm{~S} \mathrm{~cm}^{-1}$ in the 1 mass\% nanotube composite and to $7 \mathrm{~S} \mathrm{~cm}^{-1}$ for the $\mathrm{MWCNT}^{-\mathrm{NH}_{2}}$ buckypaper-based nanocomposite. Furthermore, the relative high content of functional groups in the MWCNT-COOH sample, which disrupt the $\mathrm{sp}^{2}$ structure in the nanotube walls, led to inferior properties; for instance the conductivity of the buckypaper based composite

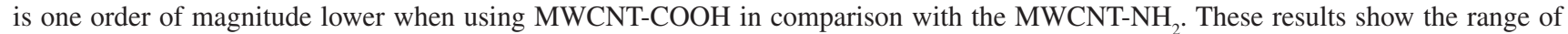
property design possibilities available with the elastomeric polyurethane nanocomposite by tailoring the functional group content and the carbon nanotube load.
\end{abstract}

Keywords: Thermoplastic polyurethane, functionalized multi-walled carbon nanotube, spray coating, buckypaper.

\section{Introduction}

Since the important works by Iijima ${ }^{[1,2]}$, carbon nanotubes (CNTs) have become key materials for the nanotechnology field because of their exceptional properties ${ }^{[3,4]}$. One of the most attractive applications of carbon nanotubes is their incorporation into polymer matrices to improve the thermal, mechanical and electrical response of high performance composites ${ }^{[5]}$. Thermoplastic polyurethane (PU) elastomers are versatile materials with excellent flexibility, elasticity, chemical resistance and processability. These properties can be tailored by changing the molecular chain structure and the content of soft segment and hard segment ${ }^{[6]}$. Polyurethanes with high electrical conductivity can be used, for instance, to design advanced formulations for electrostatic dissipation ${ }^{[7]}$ and electromagnetic shielding ${ }^{[8,9]}$. Moreover, the shape recovery of polyurethane/CNT materials has been presented as an interesting property to be explored ${ }^{[10,11]}$.

Carbon nanotubes have been introduced into many polymer matrices ${ }^{[12-16]}$. Reported methods to fabricate polyurethane/CNT composites include solution casting ${ }^{[7-9,17]}$, melting processing ${ }^{[18,19]}$ and in situ polymerization ${ }^{[11,20,21]}$. Several chemical treatments on the surface of CNTs have been shown to enhance interactions between the CNT and the polymeric matrix ${ }^{[15,17,20-22]}$. The strategies to produce nanocomposites with both high and low concentrations of CNTs must be different in order to take full advantage of the CNT properties. Low CNT contents ( $<2$ mass \%) can be dispersed successfully and distributed by the solution casting, melting mixing or other. These methods did not allow for the addition of more than 20 mass\% CNTs due to aggregation and deterioration of the desired properties. One possible strategy to form materials with high CNT concentrations is to prepare buckypapers impregnated with a polymer $\left.{ }^{[23,24}\right]$. Buckypaper films are exciting materials from the perspective of applications because they can be added to plastics and rubber part of aircrafts or automobiles to offer electromagnetic interference shielding and strike protection.

The influence of chemically functionalized MWCNTs on the properties of polyurethane/MWCNT composites prepared by spray-coating and buckypaper infiltration techniques was investigated in this study. Therefore, we have two types of nanocomposites with very distinct concentrations. Spraycoating was used to produce samples with 1 mass\% CNT, and impregnation methods were used to produce buckypaper-based materials with approximately 50 mass $\%$ nanotubes. The interplay of differences on concentration values, preparation methods and functionalization degrees of the carbon nanotubes provided a clear scenario of properties in relation to thermal and electrical requirements.

\section{Experimental}

The thermoplastic polyurethane elastomer used in this study was purchased from Bayer (TPU 990R Texin). The chemical structure of TPU was investigated by $1 \mathrm{H}$ and $13 \mathrm{C}$ Nuclear Magnetic Resonance (not shown) and confirmed to be composed mainly of 4,4-diphenylmethane diisocianate (MDI) and poly(tetramethyleneglycol). The content of hard segment was also evaluated by the NMR analyses as being between 14-20 mass \% ${ }^{[25]}$.

The short thin MWCNTs, produced by the catalytic carbon vapor deposition (CCVD) process, were provided by Nanocyl with metal residue less than 5 mass $\%$, which was confirmed by thermogravimetric (TG) analysis (Figure 1c). Two types of MWCNT were used, one of which was functionalized with carboxyl and the other was functionalized with amine groups (Figure 1b). The nanotubes have an average diameter of $10 \mathrm{~nm}$ and length of $1 \mu \mathrm{m}$ as reported by the supplier and confirmed in our studies. It is important to note that the $-\mathrm{COOH}$ content is approximately 5 mass $\%$, which was confirmed by the TG experiments, whereas the $-\mathrm{NH}_{2}$ content is approximately 0.5 mass $\%$, as reported by the supplier (XPS - X ray photoelectron spectroscopy measurement). The TG curve indicates that the amount of amino groups is less than 1 mass\% (Figure 1c). 


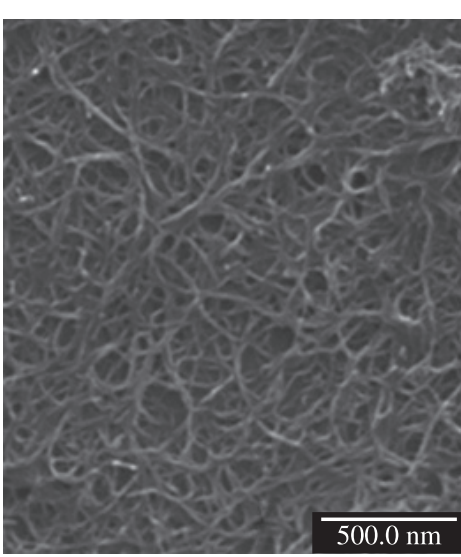

(a)

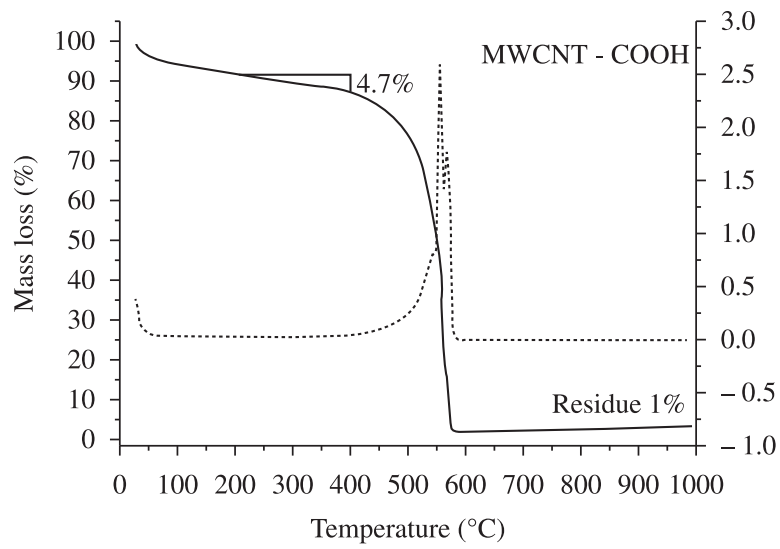

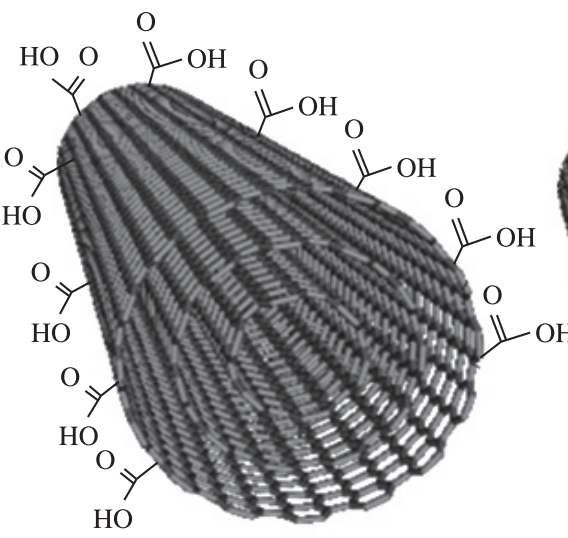

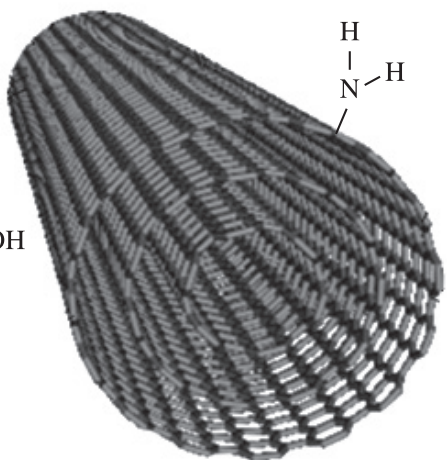

(b)

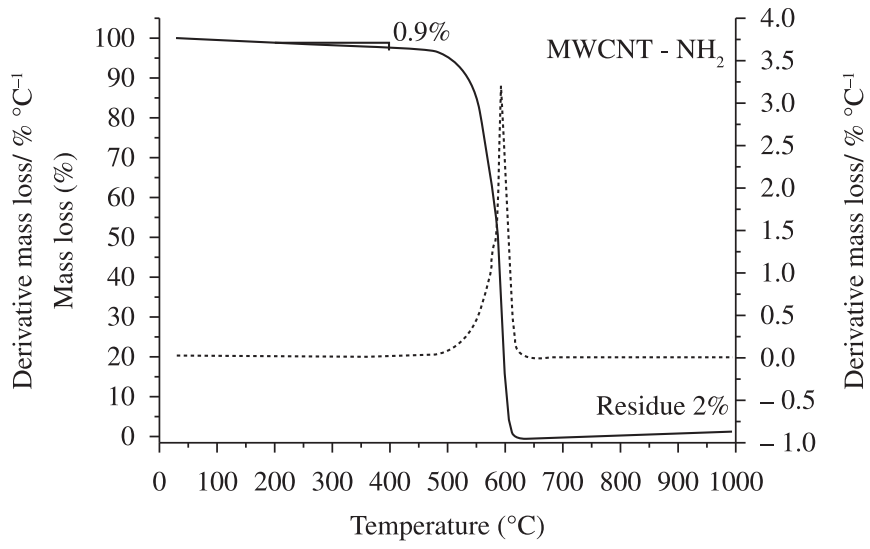

(c)

Figure 1. a) SEM image for the $\mathrm{MWCNT}-\mathrm{NH}_{2}$; b) schematic representation of the functionalization degree in $\mathrm{MWCNT}-\mathrm{COOH}$ and $\mathrm{MWCNT}-\mathrm{NH} \mathrm{H}_{2}$; c) thermogravimetric (TG) curves for both. The TG was performed in dry synthetic air at $5{ }^{\circ} \mathrm{C} / \mathrm{min}$.

\section{Composite preparation}

Both spray-coating and impregnation of buckypaper were used to prepare composite sample. All samples of MWCNT reinforced polymer films were produced in DMF solutions, which proved to be the most effective solve/dispersant agent. MWCNTs dispersed in DMF exhibited good stability (several days) and this stability was increased further after polyurethane addition.

\section{Fabrication of TPU/MWCNT composites by spray coating}

Exact amounts of the different MWCNTs (5 mg) were suspended in DMF. The suspension was sonicated (in a low ultrasonic bath) for 3 hours, centrifuged for 1 hour, filtered through a PTFE membrane filter ( $3 \mu \mathrm{m}$ pore size) and then used to produce a dispersion of MWCNT in the polymer. In a DMF solution $(50 \mathrm{~mL})$, TPU was dissolved to a concentration of $20 \mathrm{~g} . \mathrm{L}^{-1}$ and the resultant solution was added to the MWCNT suspension to obtain a MWCNT-to-polymer ratio of 1 mass $\%$, which was treated using a combination of longterm stirring and sonication. The solution was sprayed on stainless steel substrates and solvent evaporation was carried out at $60{ }^{\circ} \mathrm{C}$. The composites were maintained in a vacuum oven at $90{ }^{\circ} \mathrm{C}$ for 24 hours to remove residual solvent and stored in a vacuum chamber.

\section{Fabrication of TPU/MWCNT composites using buckypaper}

Approximately 20-30 mg of functionalized MWCNTs materials were dispersed in $50 \mathrm{~mL}$ DMF by treatment in a low ultrasonic bath for 4 hours. The homogeneous suspension obtained was filtered through a PTFE membrane filter and then dried. TPU solution ( 5 g. $\mathrm{L}^{-1}$ ) was allowed to pass through the carbon nanotube mat placed on the membrane for several hours to allow impregnation. The fleece like black paper (buckypaper) was removed by peeling from the filter. After infiltration, a buckypaper was soaked in the TPU solution (10 g. $\left.\mathrm{L}^{-1}\right)$ system overnight to assure complete impregnation. The composites were maintained in a vacuum oven at $90{ }^{\circ} \mathrm{C}$ for 24 hours to remove solvent and stored in a vacuum chamber.

\section{Characterization}

Differential scanning calorimetry (DSC) was carried out using a TA Instruments 2920 DSC with a scanning range from $-110{ }^{\circ} \mathrm{C}$ and $120^{\circ} \mathrm{C}$ at a heating range of $10^{\circ} \mathrm{C} / \mathrm{min}$ with a He flow rate of $50 \mathrm{~mL} / \mathrm{min}$. Two heating/cooling scans were conducted in order to evaluate the influence of possible residual solvent or adsorbed water on the thermal properties of the materials. The second DSC heat scanning was used to determine phase transitions.

Thermogravimetric (TG) measurements were performed with TA Instrument SDT 2960 simultaneous TG/DTA at a heating rate of $10{ }^{\circ} \mathrm{C} / \mathrm{min}$ with a nitrogen flow of $50 \mathrm{~mL} / \mathrm{min}$ between 25 and $1000{ }^{\circ} \mathrm{C}$. Approximately $5 \mathrm{mg}$ of the sample were used in both TG and DSC experiments.

The morphology of the composites was investigated by using a FEI Quanta 200 environmental scanning electron microscope 
(SEM). The composites were attached to an aluminum stub with the aid of double-slide carbon tape. Fracture surface images were obtained by fracturing the sample in liquid nitrogen and surface images were taken by gold coating the composites.

Electrical measurements were carried out in an Eco Chemie impedance frequency analyser Autolab PGSTAT 30 for nanocomposites produced by spray-coating and pure TPU. An experimental cell with two gold electrode collectors was used for conductivity measurements in 0.5 to $5 \times 105 \mathrm{~Hz}$ frequency range using a $50 \mathrm{mV}$ amplitude. Measurements by direct current were performed for buckypapers due to their high conductivity values. Four point measurements were carried out with a KEITHLEY 238.

\section{Results and Discussion}

The surface images of the composites produced by spraycoating (Figure 2a,b) revealed good distribution of MWCNT in the polymeric matrix similar to a previous work with the same kind of nanotube ${ }^{[26]}$. The nanotubes were more difficult to find in the images of the MWCNT-NH $\mathrm{N}_{2}$ composite.

Figure 2c,d,e,f shows images for the composites fabricated using buckypaper. The surface images of composites (Figure 2c,e) revealed that the MWCNT are spread homogeneously over the surface. Continuous and distributed networks were formed in the composites with such a high carbon nanotube loading. The fracture surface images (Figure 2d,f) showed that the TPU matrix was impregnated throughout the buckypaper.

The buckypaper based nanocomposites prepared from carboxyl and amine functionalized nanotubes exhibited similar dense morphologies in the SEM images (Figure 2). Blighe et al. ${ }^{[23]}$ recently prepared porous buckypapers by infiltration of polystyrene. The strong interaction between functionalized nanotubes and polyurethane as well as the long period of infiltration used in this work likely resulted in the absence of porosity in our materials. Either dense or porous materials can be used as polymer materials depending on the desired properties of the final product.

\section{Thermal characterization}

Figure 3 shows the first derivative of weight loss versus temperature for the composites. The thermal degradation of TPU is a particular process as hard and soft segments may respond differently during heating ${ }^{[19,27,28]}$. In the case of the low hard segment content TPU investigated in this work, however, it was not possible to distinguish between specific mass losses associated to each domain. The polyurethane exhibited two main stages of decomposition in $\mathrm{N}_{2}$ as showed in Figure 3. The first decomposition temperature (at $326^{\circ} \mathrm{C}$ ) did not appreciably change, although it showed decoupled behavior, whereas the second decomposition temperature increased with the addition of 1 mass $\%$ of MWCNT to spray-coating composites from 398 to 412 and $421^{\circ} \mathrm{C}$ for MWCNT$\mathrm{COOH}$ and $\mathrm{MWCNT}-\mathrm{NH}_{2}$, respectively. An increase in thermal stability was observed for other polyurethane/CNT composites with a low content of nanotubes ${ }^{[19,27,28]}$. This behavior may be attributed to the high thermal stability of CNT and a favorable interaction between the MWCNT and the polyurethane chains ${ }^{[27,29]}$.

Figure $3 \mathrm{c}, \mathrm{d}$ shows the first derivative of weight loss versus temperature for the composites prepared from buckypaper. As the polyurethane degrades in nitrogen the concentration of MWCNT can be estimated from the residue. The concentrations of MWCNTs are approximately 52 mass $\%$ for MWCNT-COOH and 55 mass\% for MWCNT-NH.

The thermal stability for the buckypaper based nanocomposites showed as general trend, a slightly decrease in comparison with neat
TPU. This is a surprising behavior in comparison with the results for the 1 mass \% nanotube composites. The buckypaper composite behavior can be a consequence of the high thermal conductivity of the carbon nanotubes ${ }^{[30]}$ leading to a very efficient heat transfer across the whole sample and increasing the decomposition rate at lower temperatures, during the thermogravimetric run.

The flexibility of polyurethane chemistry leads to complex situations where, in a single sample, it is possible to have a softsegment glass transition, a soft-segment melting point, a hardsegment glass transition and a hard-segment melting point ${ }^{[6,17]}$. This was not the case for the TPU investigated in the present work, however, because soft segments did not display melting behavior. Three thermal transitions were observed as shown in Figure 4. The glass transition temperature for the TPU soft segment domain at $-42{ }^{\circ} \mathrm{C}$ is the best defined, which is expected due to the higher concentration of this phase. The hard segment domains showed a glass transition temperature at $45^{\circ} \mathrm{C}$ and a broad endothermic event at around $168^{\circ} \mathrm{C}$.

The effect of the modified MWCNTs on the calorimetric behavior of the TPU matrix is presented in Figure 4. The features related to the spray-coated 1 mass $\%$ composites will be discussed first. The DSC curves in Figure 4a and the data in Table 1 indicate that the glass transition region related to the hard segments domain shifted to higher temperature with MWCNT- $\mathrm{NH}_{2}$ compared to the neat TPU (from 45 to $55{ }^{\circ} \mathrm{C}$ ). This trend was also observed for the melting of the hard segments (from 168 to $182{ }^{\circ} \mathrm{C}$ ). This result

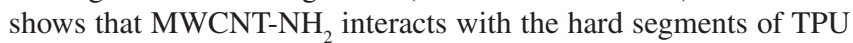
chains and makes the polymer chain mobility more difficult. In contrast, in comparison with the neat TPU, the $T g$ decreased from 45 to $36{ }^{\circ} \mathrm{C}$ for the TPU/MWCNT-COOH composite.

Opposite behaviors of glass transition increase or decrease have been observed for polyurethane nanocomposites ${ }^{[17,19,21,28]}$, as well as for other polymer composites with carbon nanotubes ${ }^{[31]}$. Korley and co-workers ${ }^{[6]}$ reported the preferential association of silicate layers in segmented polyurethane nanocomposites with high hard segments contents (33 to 40 mass\%). They showed that depending on the clay loading and hydrophilicity of the domains, the silicate disks were preferentially embedded within either the soft or hard domains. This partitioning of the clay platelets into the domains, however, is not absolute.

The material with 1 mass $\%$ of CNTs showed opposite behaviors for the hard segment glass transition with the addition of MWCNT functionalized with $-\mathrm{NH}_{2}$ and $-\mathrm{COOH}$. As previously discussed, these functionalized materials have very different functional group contents: 5 mass $\%$ of $-\mathrm{COOH}$ and $\sim 0.5$ mass $\%$ of $-\mathrm{NH}_{2}$. Therefore, the carboxyl-functionalized nanotubes are active in disrupting the internal organization of the hard segments, whereas the amine functionalized help in confining and increase order in the nanocomposites hard segment domains. As the degree of functionalization differs by a factor of 10 (see Figure 1), it is

Table 1. DSC data for neat TPU and nanocomposites prepared with functionalized MWCNT.

\begin{tabular}{lccc}
\hline \multicolumn{1}{c}{ Samples } & $\begin{array}{c}\boldsymbol{T g} \text { soft } \\
\text { segment } /{ }^{\circ} \mathbf{C}\end{array}$ & $\begin{array}{c}\mathbf{T g} \text { hard } \\
\text { segment } /{ }^{\circ} \mathbf{C}\end{array}$ & $\begin{array}{c}\text { Tm } \text { } \\
\text { segment } /{ }^{\circ} \mathbf{C}\end{array}$ \\
\hline Neat TPU & -42 & 45 & 168 \\
TPU/MWCNT-COOH 1 mass\% & -42 & 36 & 167 \\
TPU/MWCNT-NH 1 1 mass\% & -46 & 55 & 181 \\
$\begin{array}{l}\text { TPU/MWCNT-COOH } \\
\text { buckypaper }\end{array}$ & $\sim-41^{*}$ & 40 & - \\
$\begin{array}{l}\text { TPU/MWCNT-NH } \\
\text { buckypaper }\end{array}$ & $\sim-30^{*}$ & 47 & - \\
\hline
\end{tabular}

*difficult to define because of the small heat capacity variation during transition. 


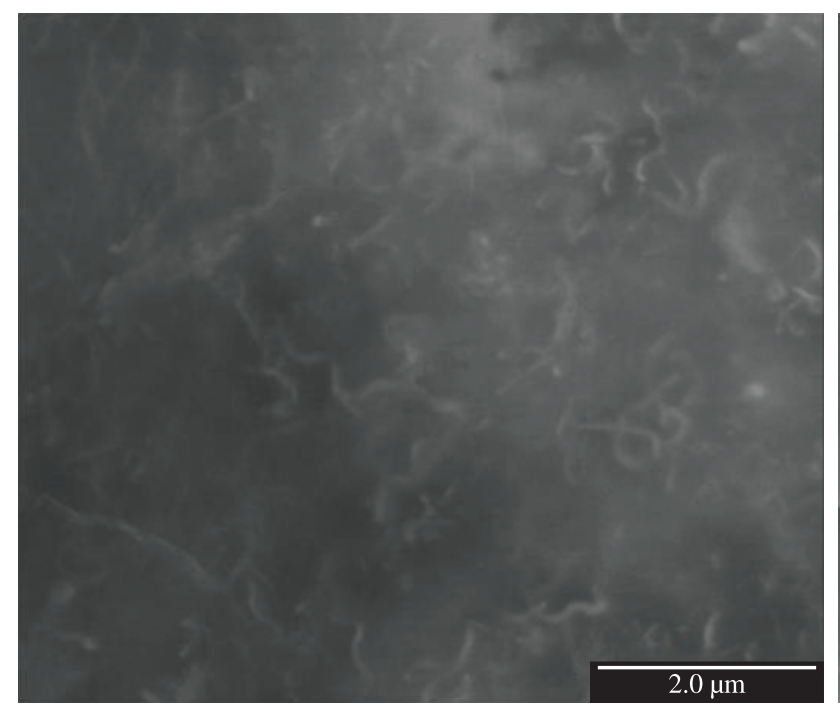

(a)

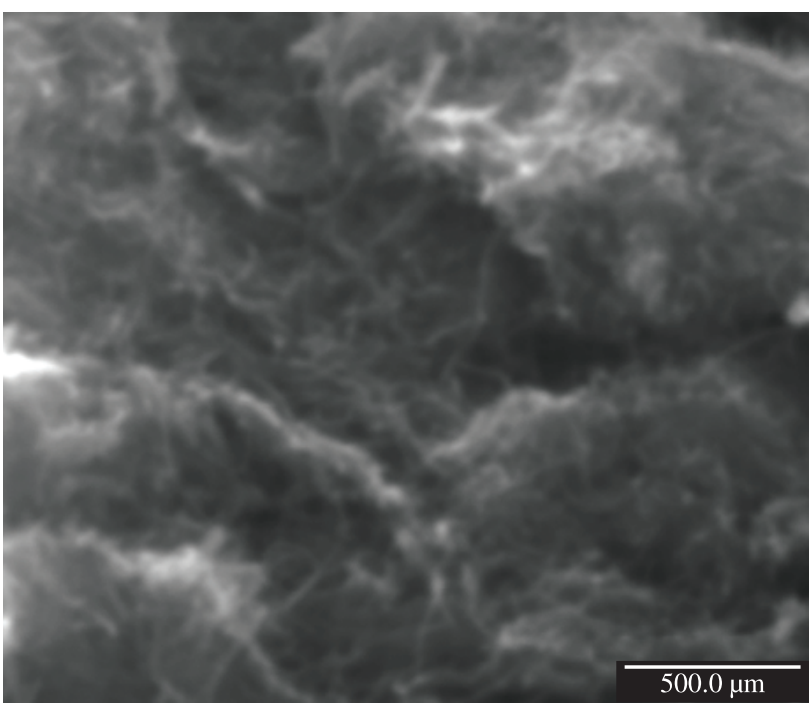

(c)

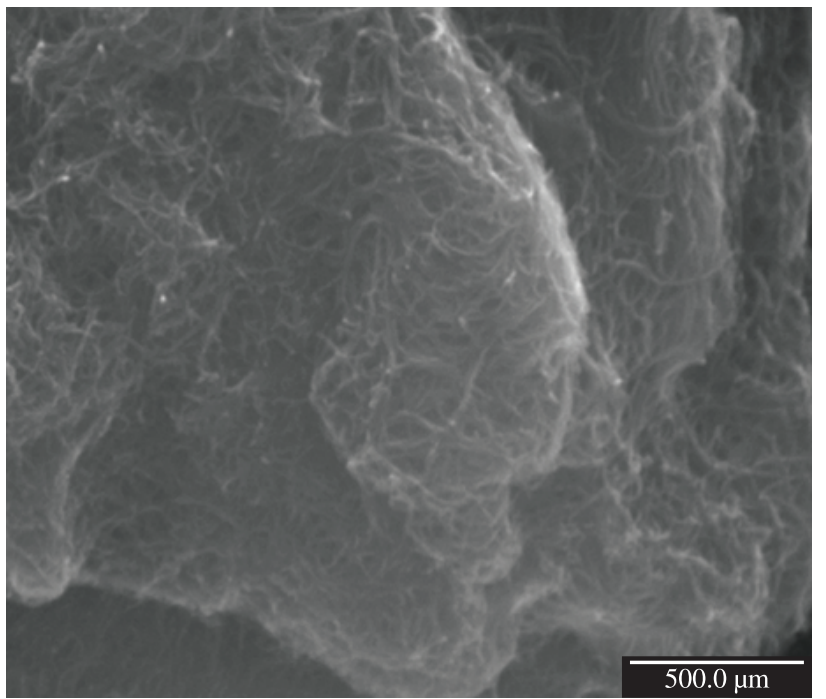

(e)

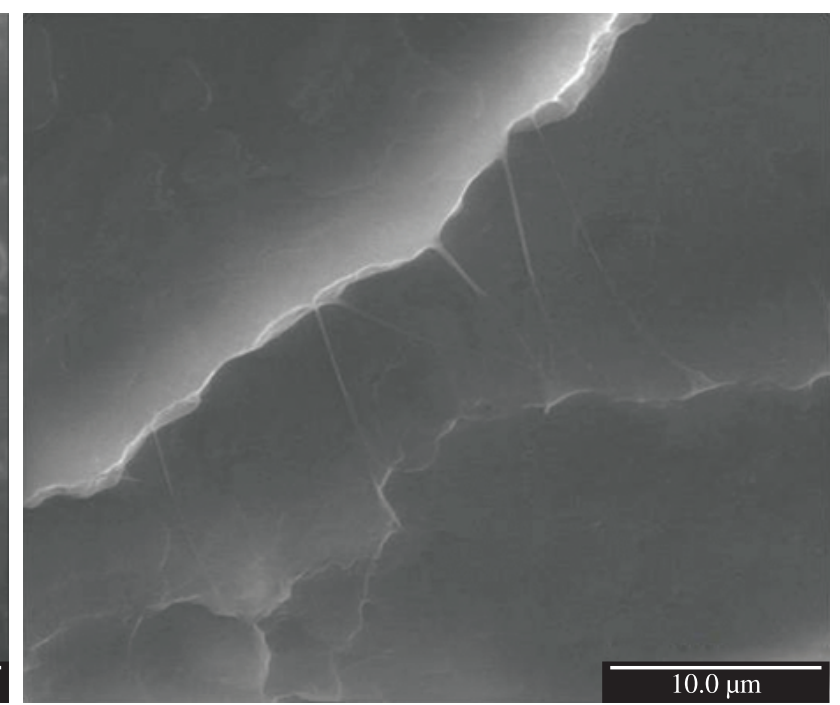

(b)

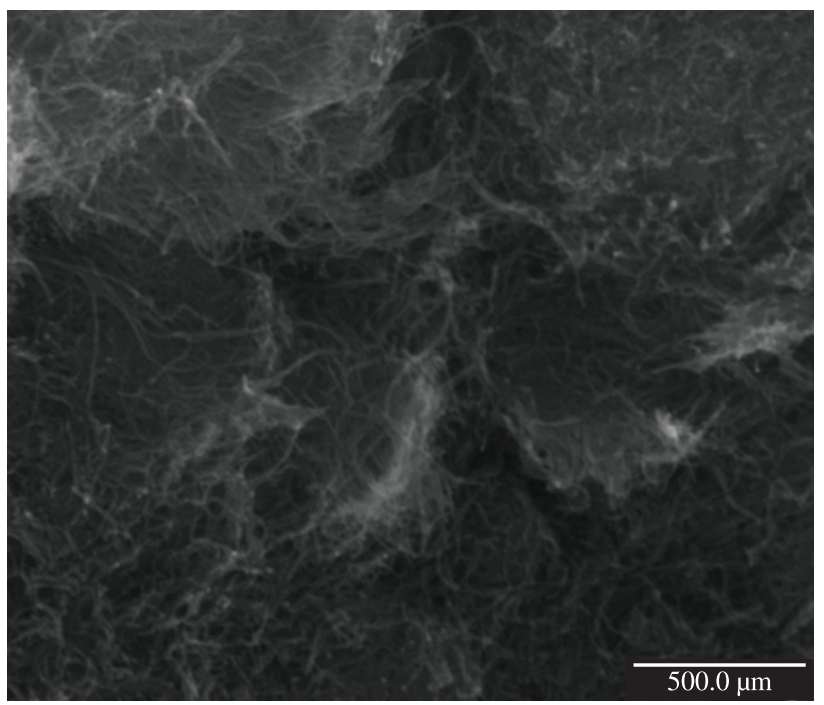

(d)

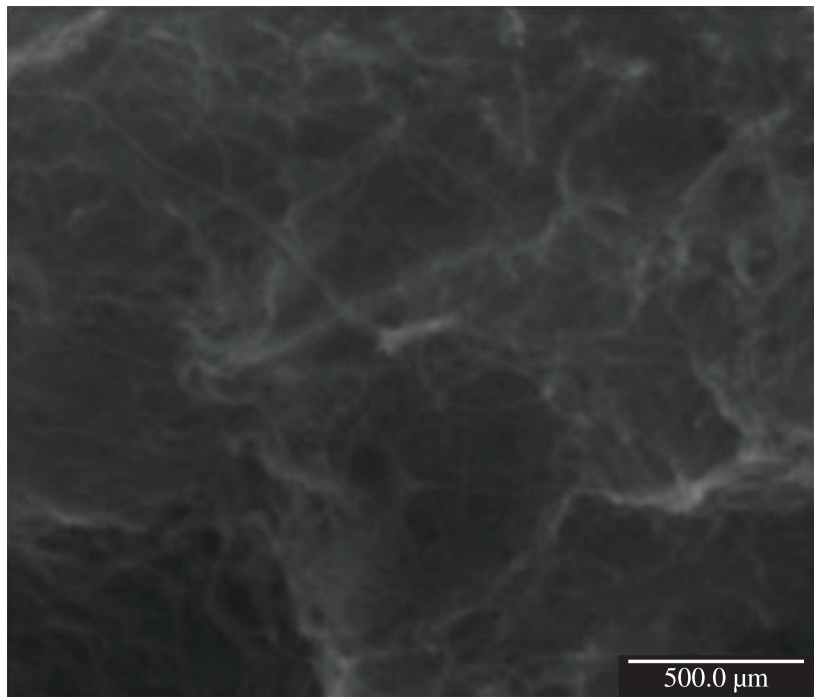

(f)

Figure 2. SEM images for TPU/spray coating composite surface with 1 mass $\%$ of a) MWCNT-COOH and b) MWCNT-NH ${ }_{2}$; TPU/buckypaper MWCNT-COOH composite c) surface and d) fracture and TPU/buckypaper MWCNT-NH $\mathrm{N}_{2}$ composite e) surface and f) fracture. 


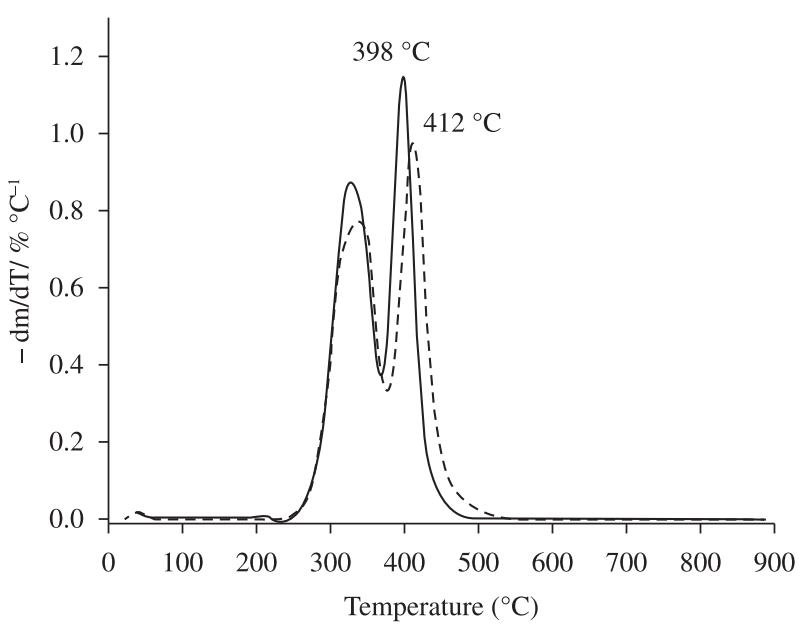

- TPU --- TPU_MWCNT - COOH

(a)

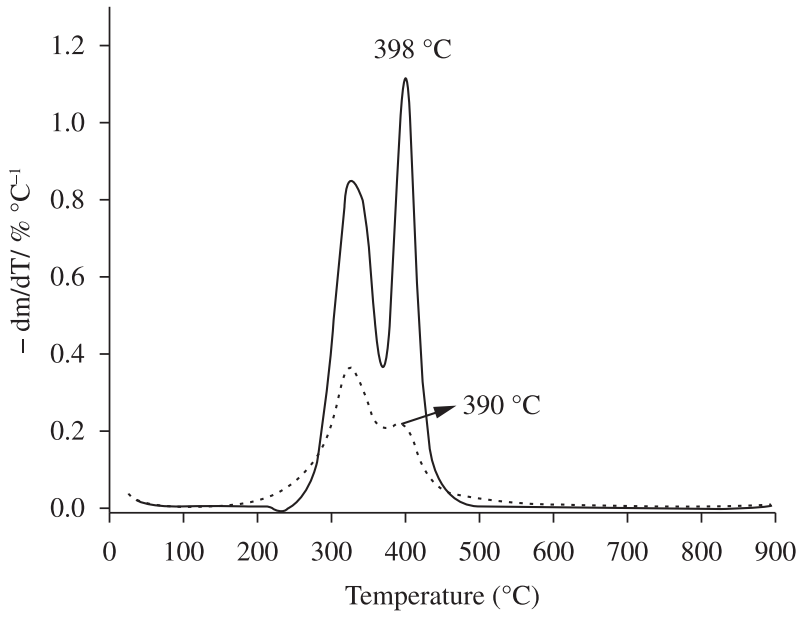

— TPU $\cdots . .$. TPU/MWCNT - $\mathrm{COOH}$

(c)

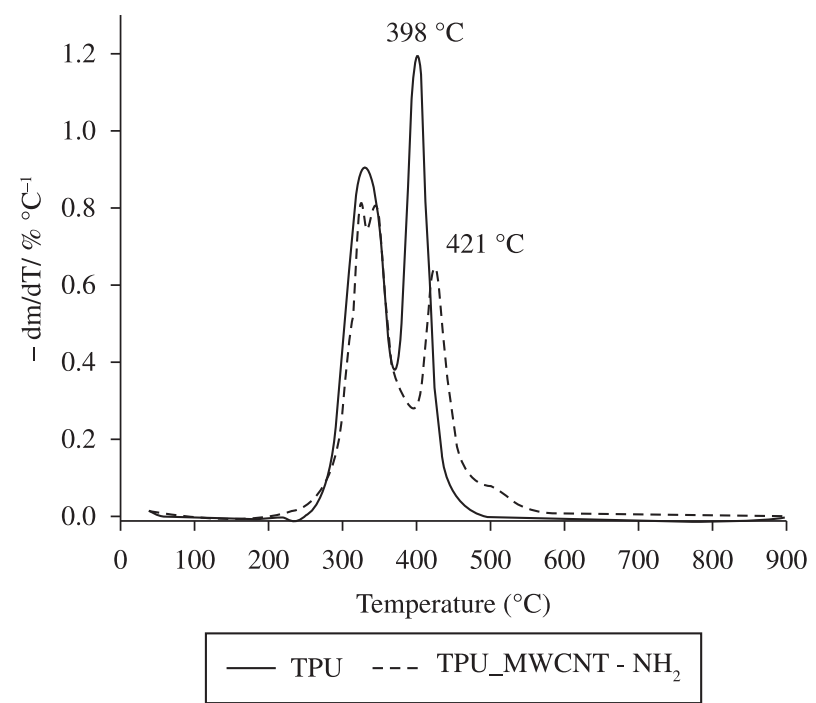

(b)
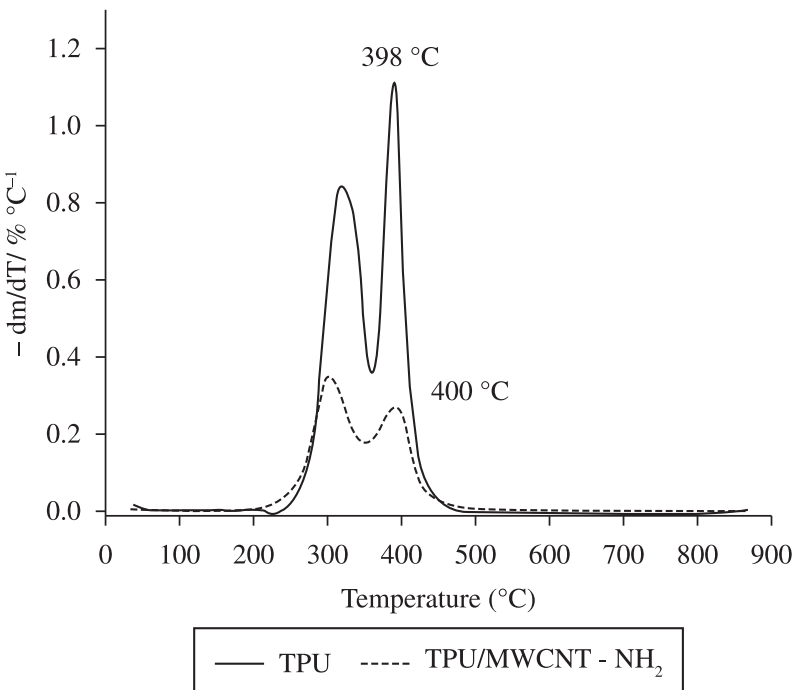

(d)

Figure 3. Derivative thermogravimetric curves for TPU/spray-coating composite with 1 mass $\%$ of a) MWCNT-COOH and b) MWCNT-NH; composite with $\sim 50$ mass $\%$ of c) MWCNT-COOH and d) MWCNT- $\mathrm{NH}_{2}$.

difficult to draw conclusions about the influence of specific chemical characteristics of these functional groups. However, it may be the case that an amino group will interact more efficient with the hard segment of the PU.

Composites fabricated from buckypaper show the same trend observed for the spray-coated materials, although less pronounced, in the case of hard segment domains. The hard segment glass transition for the buckypaper based composites containing MWCNT-COOH and MWCNT-NH $\mathrm{N}_{2}$ are 40 and $47{ }^{\circ} \mathrm{C}$, respectively (Table 1). It was not possible to determine a calorimetric event at temperatures higher than $160{ }^{\circ} \mathrm{C}$ for these materials. The most interesting feature observed for the buckypaper based nanocomposites in Figure $4 \mathrm{~b}$ is the important decrease in the heat capacity change during soft segment domains glass transition at approximately $-30{ }^{\circ} \mathrm{C}$ (amine functionalized MWCNT) and $-41{ }^{\circ} \mathrm{C}$ (carboxyl functionalized) in comparison with the TPU. These temperatures are not accurate values because the plateau change during glass transition event is spread and small, although this is not the case for the 1 mass $\%$ nanocomposite shown in Figure 4. However, the heat capacity change, i.e. the step in the baseline through $T g$ showed in the region marked at Figure $4 b$, decreases for the composites, which is a strong evidence that a high loading of nanotubes hinder the polymer chains mobility by the interactions between the high surface area of nanotubes and the soft segment domains in the TPU which are in higher concentration. The buckypaper impregnation probably proceeds through capillarity driving forces, and more specific polymer chains/nanotube surface chemical interactions may be present in the spray-coated material.

\section{Electrical measurements}

Table 2 shows the conductivity results obtained by impedance spectroscopy for neat TPU and spray-coated nanocomposites. The impedance spectra for the composites showed an approximately constant real part of impedance ( $\left.Z^{\prime}\right)$ as a function of frequency, which was used to determine conductivity. Moreover, a four point method was applied to determine the conductivity, as an average 


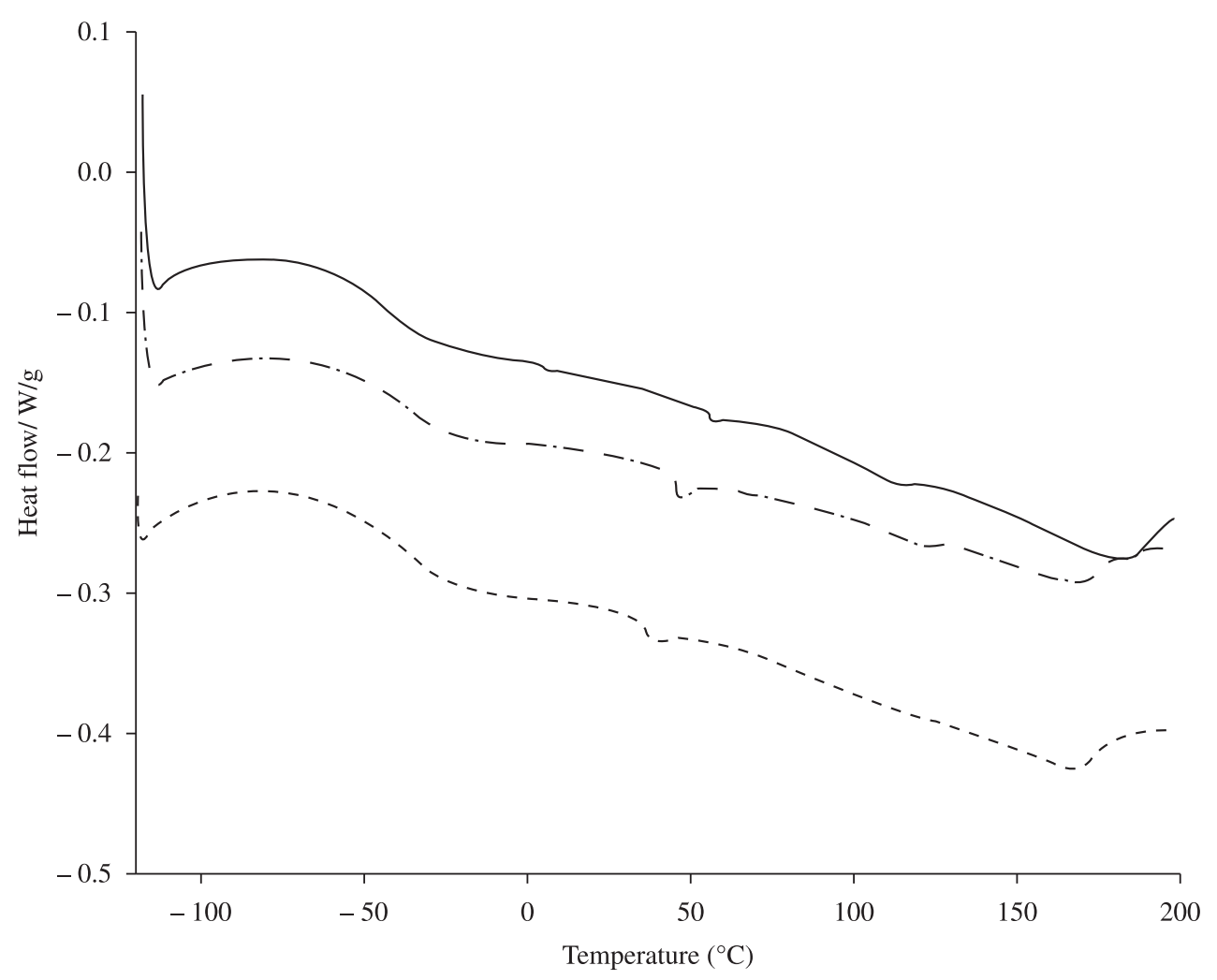

(a)

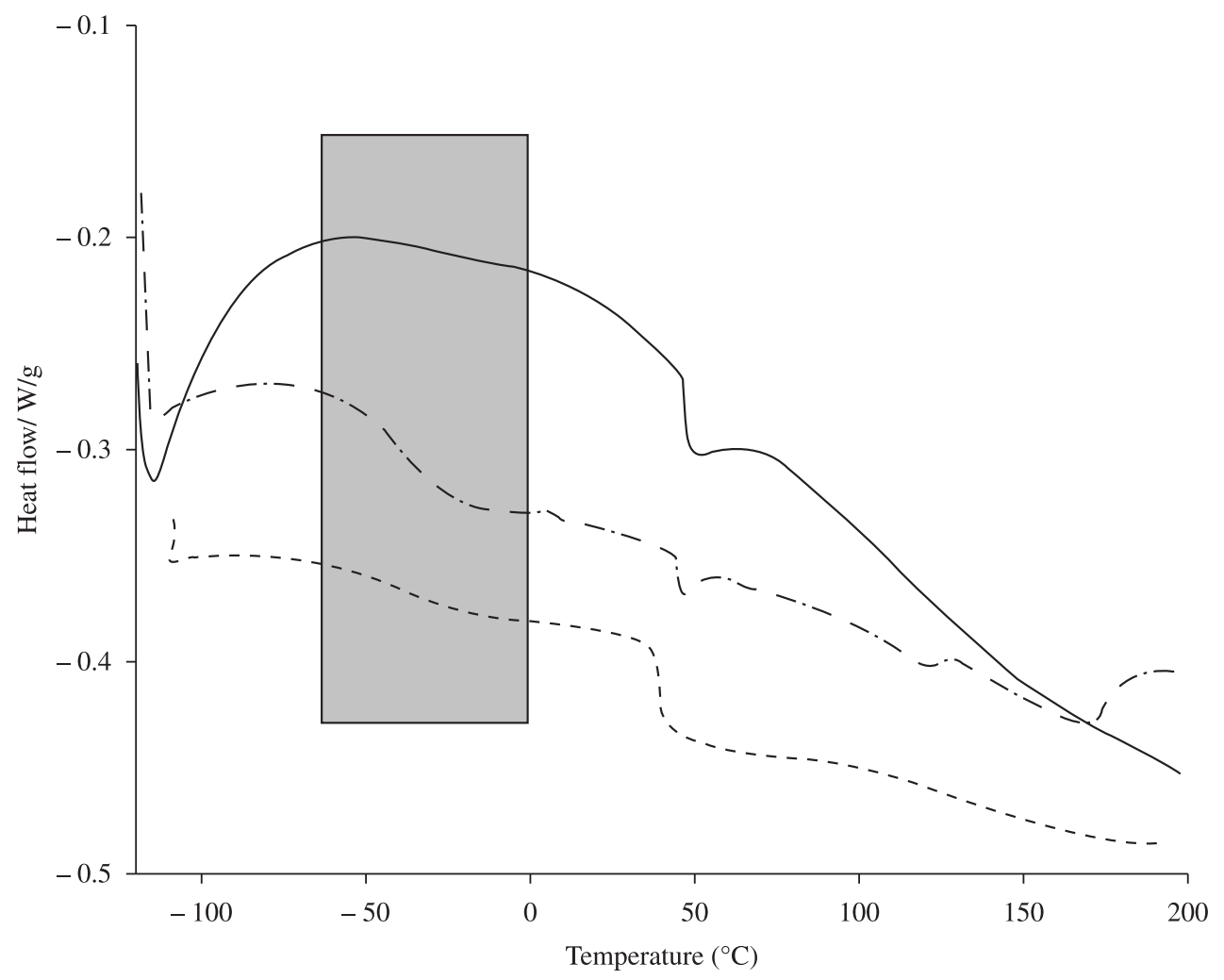

(b)

$$
\text { -.- TPU - - - TPU/MWCNT - } \mathrm{COOH}-\text { TPU/MWCNT - } \mathrm{NH}_{2}
$$

Figure 4. DSC curves for TPU and its composites fabricated by a) spray coating (1 mass \% nanotubes) and b) buckypaper based ( $>50$ mass $\%$ nanotubes). The box in b) is showing the region of the soft segment glass transition where the changes in baseline are smaller for the composites in comparison to the neat PU. 
Table 2. Conductivity results for TPU and nanocomposites prepared by spray-coating and using buckypapers with different MWCNTs.

\begin{tabular}{lc}
\hline \multicolumn{1}{c}{ Samples } & Conductivity $\left(\mathbf{S . c m}^{-1}\right)$ \\
\hline Neat TPU & $1.5 \times 10^{-12}$ \\
TPU/MWCNT-COOH 1 mass\% & $1.22 \times 10^{-5}$ \\
TPU/MWCNT-NH ${ }_{2}$ 1 mass\% & $2.44 \times 10^{-5}$ \\
TPU/MWCNT-COOH buckypaper & 1.1 \\
TPU/MWCNT-NH & buckypaper \\
\hline
\end{tabular}

value of measurements in five different regions of the buckypaper based composites. For nanocomposites from spray-coating, the use of only 1 mass $\%$ of MWCNT in the matrix leads to a conductivity increase from $10^{-12}$ to $10^{-5} \mathrm{~S} \mathrm{~cm}^{-1}$ at room temperature. These values are similar to other polyurethane/carbon nanotube composites within the experimental accuracy and considering the differences in the raw materials and preparations methods ${ }^{[7,8,17,21]}$. Percolation studies were performed extensively in the polymer/carbon nanotube composites and percolation thresholds lower than 1 mass $\%$ or even lower than 0.1 mass $\%$ are usual ${ }^{[7,26,32,33]}$.

Thermogravimetric analyses showed that buckypapers were produced with more than 50 mass \% of MWCNT and this amount was responsible for the highly elevated conductivity observed in Table 2. Blighe et al. ${ }^{[23]}$ showed levels of conductivity of $70 \mathrm{~S} \mathrm{~cm}^{-1}$ for a nanocomposite with 82 mass\% of SWCNT in polystyrene. The results in Table 2 show that unlike the spray coating sample, the buckypaper composite conductivities are limited only by the conductivity of the nanotube network and not the presence of polymer tunneling barrier ${ }^{[23,26]}$. Furthermore, the CNT with lower chemical functionalization content (Figure 1) shows higher levels of conductivity $\left(7 \mathrm{~S} \mathrm{~cm}^{-1}\right)$, which is expected since the electronic structure is preserved ${ }^{[17]}$.

The thermal properties manifested by the thermal transitions as well as thermal stability and levels of conductivity will define the working range of application for nanocomposites in the case of electrostatic discharge, for instance.

\section{Conclusion}

Polyurethane/MWCNT nanocomposites were fabricated by spray-coating and impregnation of buckypaper in distinct concentrations of 1 mass $\%$ and $>50$ mass $\%$ respectively. The thermal properties behavior indicates that impregnation of the pre-established network with immobile nanotube (50 mass\%) based nanocomposites results in a differentiated interaction of the polyurethane domains with the carbon nanotubes in comparison with the composite with 1 mass\% of nanotubes. However, the fundamental structural and chemical features are quite complex and were not fully exploited in this work.

The electrical conductivity was greatly improved from $10^{-12}$ to $10^{-5} \mathrm{~S} \mathrm{~cm}^{-1}$ for the spray-coating composites and to 1.1 and $7.3 \mathrm{~S} \mathrm{~cm}^{-1}$ for the buckypaper composites with MWCNT-COOH and MWCNT-NH, respectively.

Another interesting conclusion of this work is that thermal and electrical properties seem very sensitive to the degree of functionalization and maybe also to the chemical nature of the functional group. In summary, the composites produced with MWCNT- $\mathrm{NH}_{2}$, with only 0.5 mass $\%$ of amine groups, exhibit a larger improvement of all the properties studied when compared to MWCNT-COOH, having 5 mass\% of carboxyl groups, both using spray-coating and buckypaper.

\section{Acknowledgements}

The authors wish to thank the Brazilian agencies $\mathrm{CNPq}$ (Conselho Nacional de Desenvolvimento Científico e Tecnológico) and FAPEMIG (Fundação de Amparo à Pesquisa do Estado de Minas Gerais) for the research financial support and scholarships. This work was also supported by the Rede Nacional de Pesquisa em Nanotubos de Carbono/MCT/Brazil and Petrobras.

\section{References}

1. Iijima, S. - Nature, 354, p.56(1991). http://dx.doi.org/10.1038/354056a0

2. Iijima, S. \& Ichihashi, T. - Nature, 363, p.60 (1993). http://dx.doi. org/10.1038/363603a0

3. Tans, S. J.; Verschueren, A. R. M. \& Dekker, C. - Nature, 393, p.49 (1998). http://dx.doi.org/10.1038/29954

4. Wong, E. W.; Sheehan, P. E. \& Lieber, C. M. - Science., 277, p.1971 (1997). http://dx.doi.org/10.1126/science.277.5334.1971

5. Endo, M.; Strano, M. S. \& Ajayan, P. M. - "Potential applications of carbon nanotubes", in: Carbon nanotubes, Topics Appl. Physics, 111, p.13, Jorio, A.; Dresselhaus, M. S. \& Dresselhaus, G. (eds.), SpringerVerlag Berlin Heidelberg, Berlin (2008).

6. Korley, L. T. J.; Liff, S. M.; Kumar, N.; McKinley, G. H. \& Hammond, P. T. - Macromolecules., 39, p.7030 (2006).

7. Koerner, H.; Liu, W. D.; Alexander, M.; Mirau, P.; Dowty, H. \& Vaia, R. A. - Polymer., 46, p.4405 (2005). http://dx.doi.org/10.1016/j. polymer.2005.02.025

8. Liu, Z. F.; Bai, G.; Huang, Y.; Ma, Y. F.; Du, F.; Li, F. F.; Guo, T. Y. \& Chen, Y. S. - Carbon. 45, p.821 (2007). http://dx.doi.org/10.1016/j. carbon.2006.11.020

9. Ma, C. C. M.; Huang, Y. L.; Kuan, H. C. \& Chiu, Y. S. - J. Polym. Sci. Part B Polym. Phys., 43, p.345 (2005). http://dx.doi.org/10.1002/ polb. 20330

10. Koerner, H.; Price, G.; Pearce, N. A.; Alexander, M. \& Vaia, R. A. - Nat. Mater., 3, p.115 (2004). PMid:14743213. http://dx.doi. org/10.1038/nmat 1059

11. Meng, Q. M.; Hu, J. L. \& Zhu, Y. - J. Appl. Polym. Sci., 106, p.837 (2007). http://dx.doi.org/10.1002/app.26517

12. Ajayan, P. M. \& Tour, J. M. - Nature., 447, p.1066 (2007). PMid:17597753. http://dx.doi.org/10.1038/4471066a

13. Bal, S. \& Samal, S. S. - Bull. Mater. Sci., 30, p.379 (2007). http:// dx.doi.org/10.1007/s12034-007-0061-2

14. Moniruzzaman, M. \& Winey, K.I. - Macromolecules., 39, p.5194 (2006). http://dx.doi.org/10.1021/ma060733p

15. Tasis, D.; Tagmatarchis, N.; Bianco, A. \& Prato, M. - Chem. Rev., 106, p.1105 (2006). PMid:16522018. http://dx.doi.org/10.1021/cr050569o

16. Thostenson, E. T.; Ren, Z. F. \& Chou, T. W. - Compos. Sci. Technol., 61, p.1899 (2001). http://dx.doi.org/10.1016/S0266-3538(01)00094-X

17. Buffa, F.; Abraham, G. A.; Grady, B. P. \& Resasco, D. - J. Polym. Sci. Part B Polym. Phys., 45, p.490 (2007). http://dx.doi.org/10.1002/ polb. 21069

18. Abdullah, S. A.; Iqbal, A. \& Frormann, L. - J. Appl. Polym. Sci., 110, p.196 (2008). http://dx.doi.org/10.1002/app.28479

19. Xiong, J. W.; Zheng, Z.; Qin, X. M.; Li, M.; Li, H. Q. \& Wang, X. L. - Carbon., 44, p.2701 (2006). http://dx.doi.org/10.1016/j. carbon.2006.04.005

20. Jung, Y. C.; Sahoo, N. G. \& Cho, J. W. - Macromol. Rapid. Commun., 27, p.126 (2006). http://dx.doi.org/10.1002/marc.200500658

21. Kwon, J. \& Kim, H. - J. Polym. Sci. Part A Polym. Chem., 43, p.3973 (2005). 
22. Wang, T. L.; Tseng, C. G. - J. Appl. Polym. Sci, 105, p.1642 (2007). http://dx.doi.org/10.1002/app.26224

23. Blighe, F. M.; Hernandez, Y. R.; Blau, W. J. \& Coleman, J. N. - Adv. Mater., 19, p.4443 (2007). http://dx.doi.org/10.1002/adma.200602912

24. Wang, Z.; Liang, Z. Y.; Wang, B.; Zhang, C. \& Kramer, L. - Compos. Part A Appl. Sci. Manuf., 35, p.1225 (2004). http://dx.doi.org/10.1016/j. compositesa.2003.09.029

25. Lavall, R. L.; Sales, J. A.; Borges, R. S.; Calado, H. D. R.; Machado, J. C.; Windmoller, D.; Silva, G. G.; Lacerda, R. G. \& Ladeira, L. O. - Quim. Nova., 33, p.133 (2010). http://dx.doi.org/10.1590/S010040422010000100025

26. Musumeci, A. W.; Silva, G. G.; Liu, J. W.; Martens, W. N. \& Waclawik, E. R. - Polymer., 48, p.1667 (2007). http://dx.doi.org/10.1016/j. polymer.2007.01.027

27. Mondal, S. \& Hu, J. L. - J. Elastom. Plast., 38, p.261 (2006).

28. Xia, H. S. \& Song, M. - Soft Matter., 1, p.386 (2005). http://dx.doi. org/10.1039/b509038e
29. Raravikar, N. R.; Schadler, L. S.; Vijayaraghavan, A.; Zhao, Y. P.; Wei, B. Q. \& Ajayan, P. M. - Chem. Mater., 17, p.974 (2005). http://dx.doi. org/10.1021/cm0485254

30. Berber, S.; Kwon, Y. K. \& Tomanek, D. - Phys. Rev. Lett., 84, p.4613 (2000). PMid:10990753. http://dx.doi.org/10.1103/ PhysRevLett.84.4613

31. Putz, K. W.; Palmeri, M. J.; Cohn, R. B.; Andrews, R. \& Brinson, L. C. Macromolecules, 41, p.6752 (2008). http://dx.doi.org/10.1021/ma800830p

32. Du, F. M.; Scogna, R. C.; Zhou, W.; Brand, S.; Fischer, J. E. \& Winey, K. Y. - Macromolecules 37, p.9048 (2004). http://dx.doi.org/10.1021/ ma049164g

33. Gojny, F. H.; Wichmann, M. H. G.; Fiedler, B.; Kinloch, I. A.; Bauhofer, W.; Windle, A. H. \& Schulte, K. - Polymer., 47, p.2036 (2006).

Enviado: 10/01/11 Reenviado: $27 / 04 / 11$ Aceito: $15 / 06 / 11$ 